\title{
Foresight in hindsight
}

\author{
PJ Lombard GHD Pty Ltd, Australia
}

\begin{abstract}
Historically, when an orebody was exhausted, production ceased and mines were boarded up and abandoned. The norm today is that mine closure requires the return of the land to a viable post-mining use, such as agriculture or other forms of repurposing that will benefit all the stakeholders. Baseline closure that merely reclaims mined out areas is no longer a preferred outcome and the socio-economic influences of the closure needs to be assessed well in advance and managed accordingly.

A mine is often the primary provider of income, employment, and services in a local economy. The closure of a mine usually has significant impact on the wellbeing of the community. This impact is extreme in developing countries where local government lacks capacity to structure a development process that would provide alternative economic opportunities (World Bank 2002).

Sustainable development practices on mine sites can be the mechanism by which capital generated through mineral extraction is passed on to future generations (Grant et al. 2018). The World Bank (2002) lists three sustainability development practice requirements:

1. Early constructive action by mining companies to ensure that the memory of mining is not one of negative environmental and social impacts a reputation that will increasingly threaten future mining operations elsewhere.

2. The proactive involvement by local communities to ensure that the benefits from mining are sustainable for future generations.

3. The legal framework, with early planning and support to local communities by government, to ensure that the authorities are not left to manage large environmental and social legacies.

Achievable satisfactory closure outcomes for all parties will be reached through multi-stakeholder consultation including government, industry, labour, and the communities. Legislation may act as the final arbiter of any repurposing, design, or closure decisions and while mining companies are obliged to make these decisions, other stakeholders ought to use legislation to guide their decisions in the face of demands and this should be done in a transparent manner. Companies must work within the conditions associated with their licence to operate but not leave themselves open to liabilities.
\end{abstract}

Constraints in decision-making include financial limitations, community expectations, and a lack of information and time. Minority rights should be able to influence decision-making as due consideration of these rights is important, but need not be limiting. Similarly, majority rule in closure planning decisions is not essential. A successful closure planning process will ultimately lead to an agreement with government as the final arbiter.

Keywords: stakeholders, financial limitations, closure planning, legislation

\section{Introduction}

In 2003, the World Bank listed the elements of good mine closure planning (World Bank 2003). Mine planning should commence in the design phase and should contain at least the following elements:

- Times and costs.

- Specifics about the expected final landform and surface rehabilitation, including detoxification of dumps. 
- Removal of plant related structures.

- Risk assessments to assist in prioritisation.

- Cost benefit analysis of different options.

- Management plan for implementation of closure.

- Post-closure monitoring proposals.

Initial excitement and enthusiasm in a closure project team may soon dwindle as the reality of toll gating and other project-related processes start to consume time and effort. The onerous task of stakeholder engagement and agreement can test internal and external relationships to breaking point. However, once all agreements are in place, the project tasks soon detract from the initial frustrations and deliberations.

The practical implications of initial stakeholder consultation and the process thereafter, especially the lack of continued interaction between all stakeholders, may soon lead to a very challenging relationship between parties.

The discussion points presented in the paper are a result of onsite practical experience by the author in coal mines in South Africa during all the phases of concurrent rehabilitation and final closure projects. Mine closure plans and planning for mine closure has developed and intensified as the industry has grown and developed. In light of these changes, it would be prudent to refresh our thoughts with the process from the purpose of a closure plan, through the execution stages and the challenges associated with this. The opportunities and benefits of emerging technologies that will lead to best practice need to be integrated in an attempt to reduce onsite risks and costs. Most, if not all, of these points are directly applicable to all current and future closure projects.

\section{Purpose of a closure plan}

Mine closure planning should be conceived at the beginning of the life of the mine, not lead to a culture of community dependency, involve partnerships between mining companies, trade unions, the government and civil society, and have the financial and human capital to manage the plans as required especially after mine closure.

The purpose of the closure plan is to provide a live document in preparation for mine closure, which addresses identification of actions required to meet legal requirements and other obligations in the closure of the site. This would be followed by the facilitation of a process whereby different post-closure land-use alternatives and options are considered during the planning and design stages and in consultation with stakeholders.

Of great importance is the documentation of the proposed closure design and methodology for the site, taking into consideration the current level of understanding of risks and uncertainties. Documentation of the status of the level of the design and planning progressing from conceptual through to detailed design and project execution as well as the identification of significant closure risks and mitigating actions should be continues as the project develop.

A complete gap analysis in current knowledge and identification of future actions/research should be conducted to assist in addressing the gaps.

The purpose of a closure plan should start with the specific corporate requirements. The commitments for closure need to include government regulation, contractual and community agreements, and corporate policy and group level requirements. Regular engagement with government departments will allow for updates and progress reports to be shared. Interactions of this nature will develop trust and a sense of purpose with a common goal. 
In the South African context, it was very well received by the various departments involved in the closure of mines. The company representatives met with departmental officials quarterly and during these meetings, there were progress updates and site visits and this facilitated the supportive atmosphere for discussions regarding new and persistent challenges in the closure realm. There should be clear communication to all stakeholders regarding these commitments and requirements.

Completion criteria for post-closure land use and infrastructure alternatives need to be agreed on between all stakeholders at the earliest stages of the project.

Site closure at the end of an asset's life, and an optimised base plan should be communicated. This includes the development of a closure schedule and table of actions with associated accountability and timing, which are aligned to the Life-of-Asset plan.

The optimised base plan contains details of rehabilitation and remediation to be undertaken, development of closure designs, and engineering details, where required. The plan allows for the review of deconstruction and demolition for all plant and equipment, treatment, and disposal of wastes. This vision is to meet community and government expectations and possibly allow for an employment strategy to ensure the closure project is developed and executed.

The development of a community and external relations plan for closure, monitoring, and review programs to verify achievement of closure criteria should be guided by a risk analysis and control process. This process will include the completion of risk assessments and the identification of controls for design and execution of the closure project to include event risks, changes to legislation and other commitments, early closure, and agreements between joint venture partners, as well as the ability to fund cash components of closure.

Development of appropriate cost estimates for the purposes of closure provisioning and for asset valuation should be an integral part of the stakeholder engagement process with transparency for ongoing review of closure provisioning/assumptions and closure activities by all affected parties. Identification of opportunities for progressive rehabilitation through integration of mining operations and closure activities and appropriate scheduling of equipment will greatly reduce timelines and the associated costs.

Facilitation of discussions with indigenous and surrounding communities and neighbouring landowners to be able to assess opportunities for community programs leading up to and after closure should be as frequent as practicably possible. The documentation of opportunities around alternative land-uses, disposal options, and closure execution methodologies that may benefit communities and identification of actions required to pursue these opportunities further needs to be recorded and integrated into the planning.

The agreement of the post-closure relinquishment requirements and the strategy to achieve this needs to be well-documented. This aligns the post-closure monitoring and maintenance program with the key performance criteria and describes how the achievement of performance requirements will be demonstrated and maintained in terms of ongoing consultation as the project matures and even transcends the initial expectations.

Closure planning and implementation are part of an integrated mine plan and are considered as critical variables when any decisions affecting mining operations are taken (Skousen \& Zipper 2014). Every mining project must consider the contribution required to create a sustainable community and environment at the time of closure. Stakeholder engagement processes need to accommodate changes in stakeholder leadership. In the South African context, it is very important to stay abreast of the changes in the political arena, especially at the municipal level where leaders are associated with factions within political parties and a sudden change of power can lead to a total disconnect in terms of the previously agreed goals and final outcomes for a closure project. 
Leadership changes more than often introduce new challenges relating to the initially agreed outcomes. In one specific example, an initial agreement to repurpose a dragline bucket repair workshop, including ancillary workshops and offices, into an industrial park (Figure 1) with significant job creation opportunities as well as training and development options did not come to fruition due to changes in leadership structure within the community stakeholder group. The new leadership halted all progress through public demonstrations by blocking access to the site and demanding to renegotiate terms and conditions with the parties involved. The delays and constantly changing goalposts challenges sensible dialogue and often ends in a complete breakdown in communication leading to a disappointing failure in achieving the initial plan.

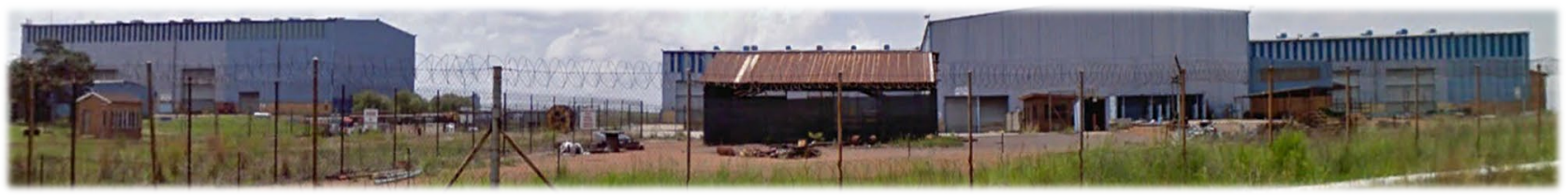

Figure 1 Dragline bucket repair workshop, ancillary workshops, and offices (Google 2010)

Facilitation of discussions relating to the expectations for closure with stakeholders and agreement on appropriate closure criteria ought to be initiated during the early stages of the project feasibility study. Efficient alternative use of mine infrastructure should be encouraged where this can be economically justified, where no economical alternative uses exist, mine infrastructure must be removed, and the site rehabilitated to pre-mining condition.

Environmental and social costs of mining operations must be considered and agreed on during the operational life of the mine to avoid high cost mining legacies at closure. Minimising dependency of the local community and economy on the mine during mine operations and allowing alternative economies to be promoted before closure will lessen the closure impacts on the local community.

Job creation through education and stimulation of economic activity (Figures 2 and 3), development projects to enable equitable participation in post-mining economies by all members of the community (especially marginalised groups). The enhancement of leadership capacity within the community and local government may be required to ensure that development continues post-closure. This can be aided by skills and literacy training for community members, where needed.
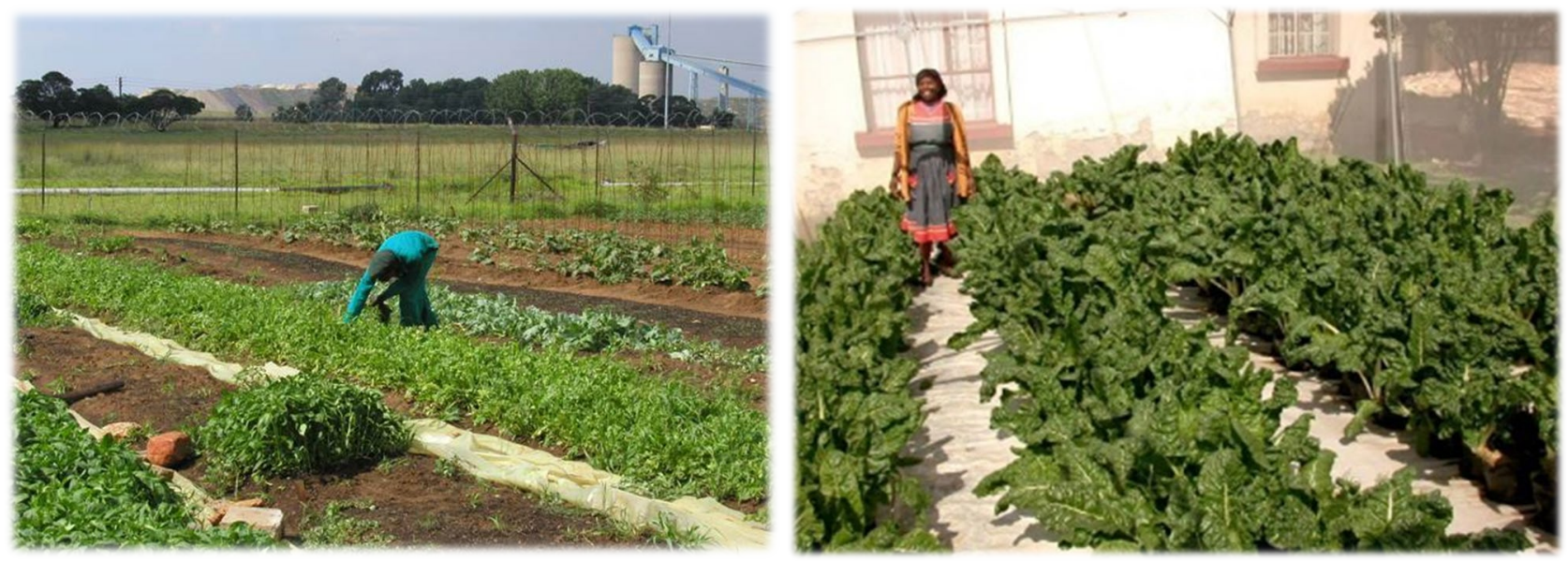

Figure 2 Self-sustaining vegetable gardens 


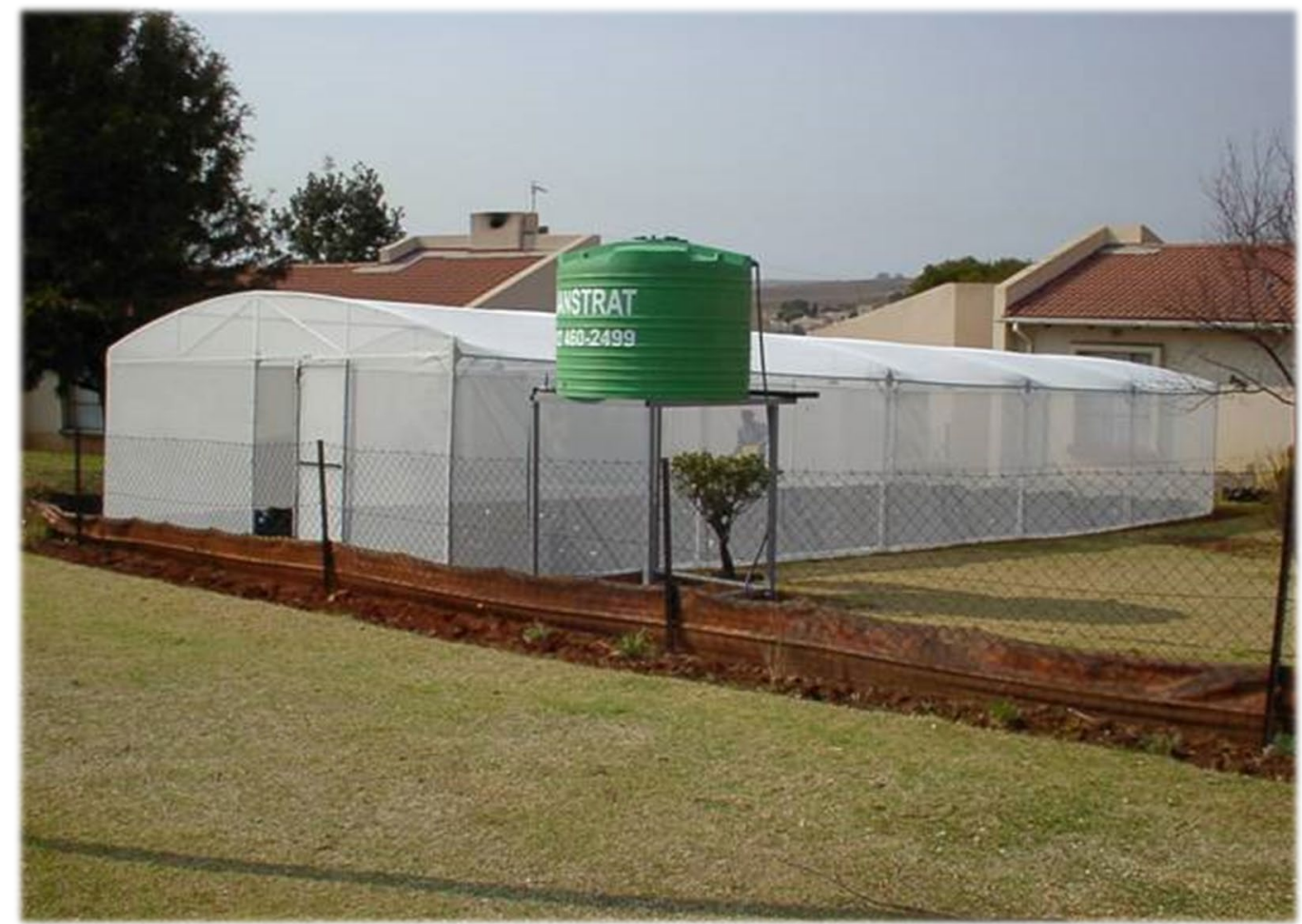

Figure 3 Hydroponic tunnels for vegetable production that facilitate job creation and economic growth

\section{The challenge: start with the end in mind}

The satisfaction of observing green rolling hills where, a few years earlier, there were mine voids and all the activities associated with large-scale mining, cannot be captured in a brief sharing like this (Figure 4)

Completed rehabilitation needs to be monitored to provide evidence of closure design performance to reduce closure provisions during operations. Implementation of achievable, effective, and optimum use of available resources and technology for closure activities should govern the closure planning and execution stages throughout the project.

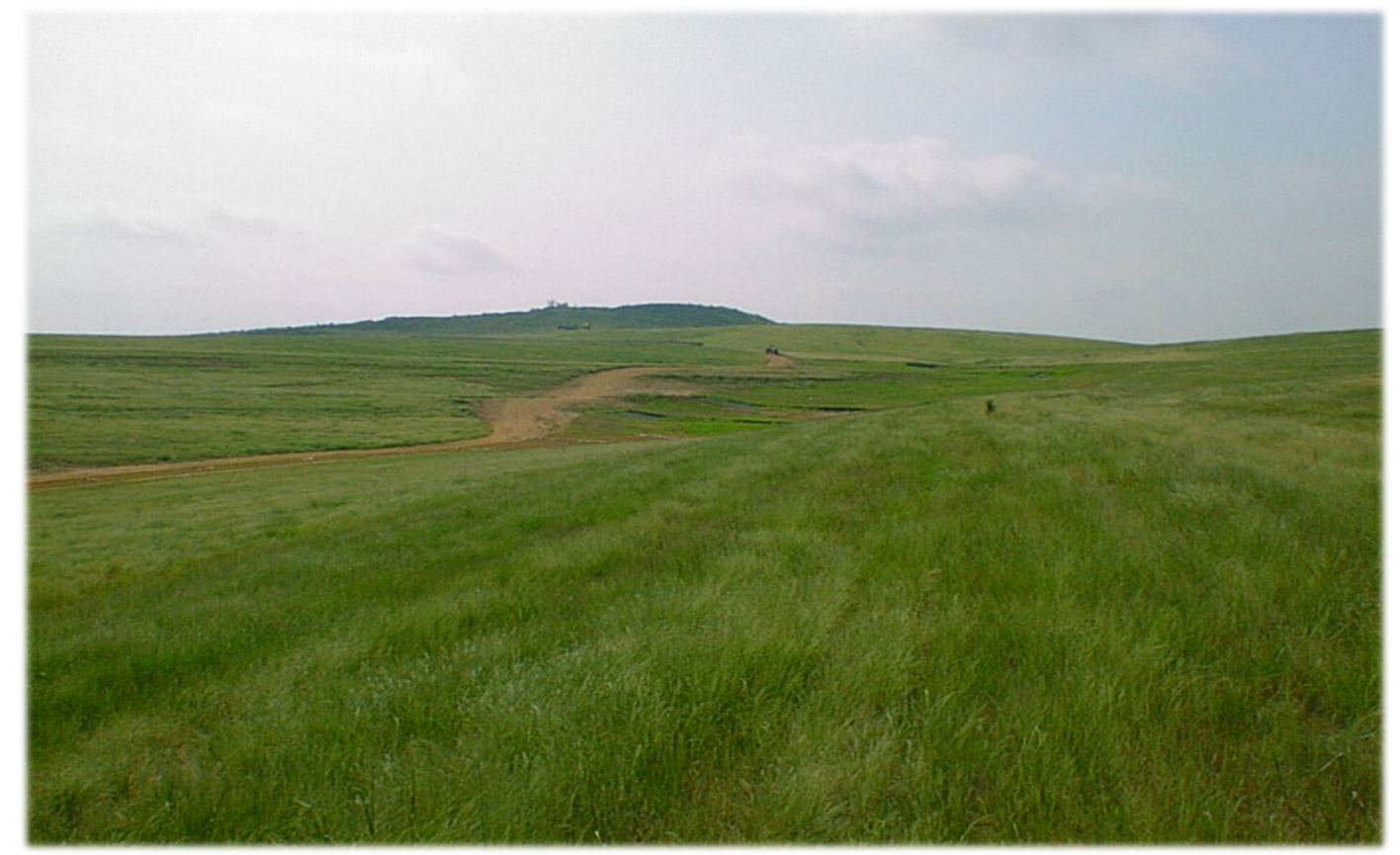

Figure 4 Pioneer grasses: second year of growth in a concurrently rehabilitated mine pit 
The amount of planning and commitment to the closure of a mine is often not clearly understood and most definitely not always fully appreciated. To close a mine successfully, a trilateral consultation and problem-solving process is required between mining companies, governments, and communities. This process needs to commence at the design stage of the project and, in doing so, the results will be evident in the cost-effective execution and sustainable legacy within that sphere of influence of each operation.

\section{Constructability, durability, and quality of all closure-related infrastructure}

The cost effectiveness of a closure project will be severely affected by poor design work and specifically steep slope designs that will challenge the practical implementations of the rehabilitation process as well as the sustainability thereof. "Quality water models and surface rehabilitation structure designs will optimise closure options" (Botha et al. 2018).

The safety, environmental, and social risks arising from poorly conducted mine closure can result in significant liabilities for mining companies. For communities, closure can cause severe distress because of the threat of economic and social collapse. Abandoned mines may result in large clean-up costs and closure liabilities for governments (World Bank 2002).

Post-mining regeneration priorities, in light of the country's developmental context, include restoration of land surface of a sufficient quality to support pre-mining land use potential, restoration of the ecological function of mined land, and, in the case of previously degraded land, the ecological function must be improved.

Slope angles largely influence the constructability which, in turn, will guide durability and ultimately produce the quality of erosion control measures that will reduce future costs in aftercare and maintenance. Initial expenditure during concurrent rehabilitation will significantly reduce closure cost provisioning (Figure 5).

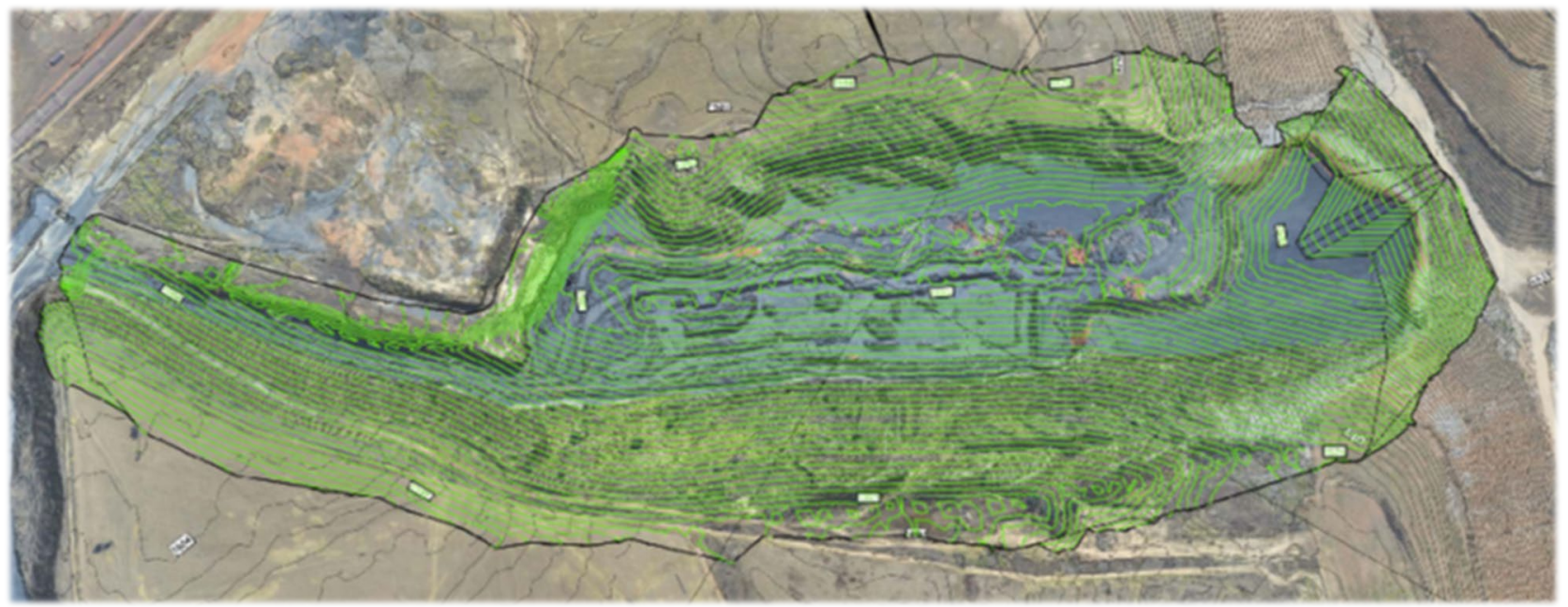

Figure 5 Final void closure design-(Source: Jones \& Wagener Engineering and Environmental Consultants)

The challenge is to convince mining, production-orientated operators of the benefits of concurrent rehabilitation and closure activities while still in the operational phase of the project.

A South African mining operation had five Draglines in production but in the early closure planning, it was agreed that one dragline would remain during the run down of production to complete the void closures. By placing the overburden back into the void from the low-wall side with the dragline and cast blasting the highwall, there were significant cost savings in terms of materials handling and time (Figure 6).

The rehabilitation/closure team's performance management key performance indicators, may be linked to rehabilitation performance based on the most effective equipment utilisation and volumes moved. Further incentives can be achieved through cost saving initiatives that may be generated by the teams. 


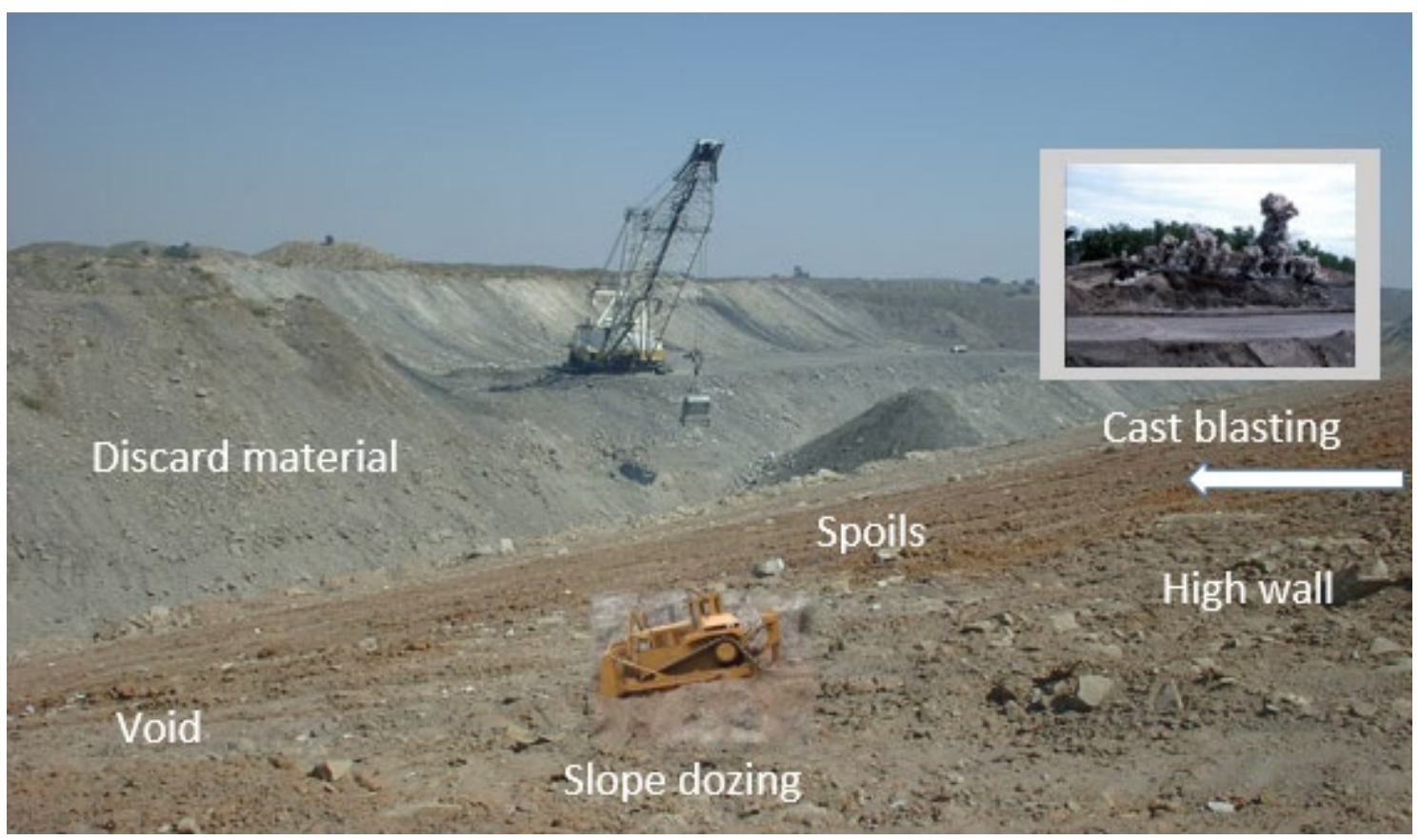

\section{Figure 6 Pit closure as per design criteria}

In instances where erosion control structures are being assessed and failures have occurred for various reasons (Figures 7 and 8), the remediation of post-closure erosion on slopes (Figure 9) will most certainly damage the existing measures put in place to assist in slope stability. Quality control throughout all the stages of the construction phases is very important in ensuring that structures are erected without any rework required.

Additional risks are re-introduced into the operation with people and equipment working in close proximity on steep slopes especially where 1:5 and steeper slopes are encountered. It is highly recommended that the construction of gabions and related structures be executed with the best materials available, particularly in conditions where acid mine drainage may occur. Premature failure of construction material will prolong care and maintenance timelines and increase the risks and costs. Failures of this nature will affect relinquishment timelines that, in turn, will affect costing and sustainability of the project.

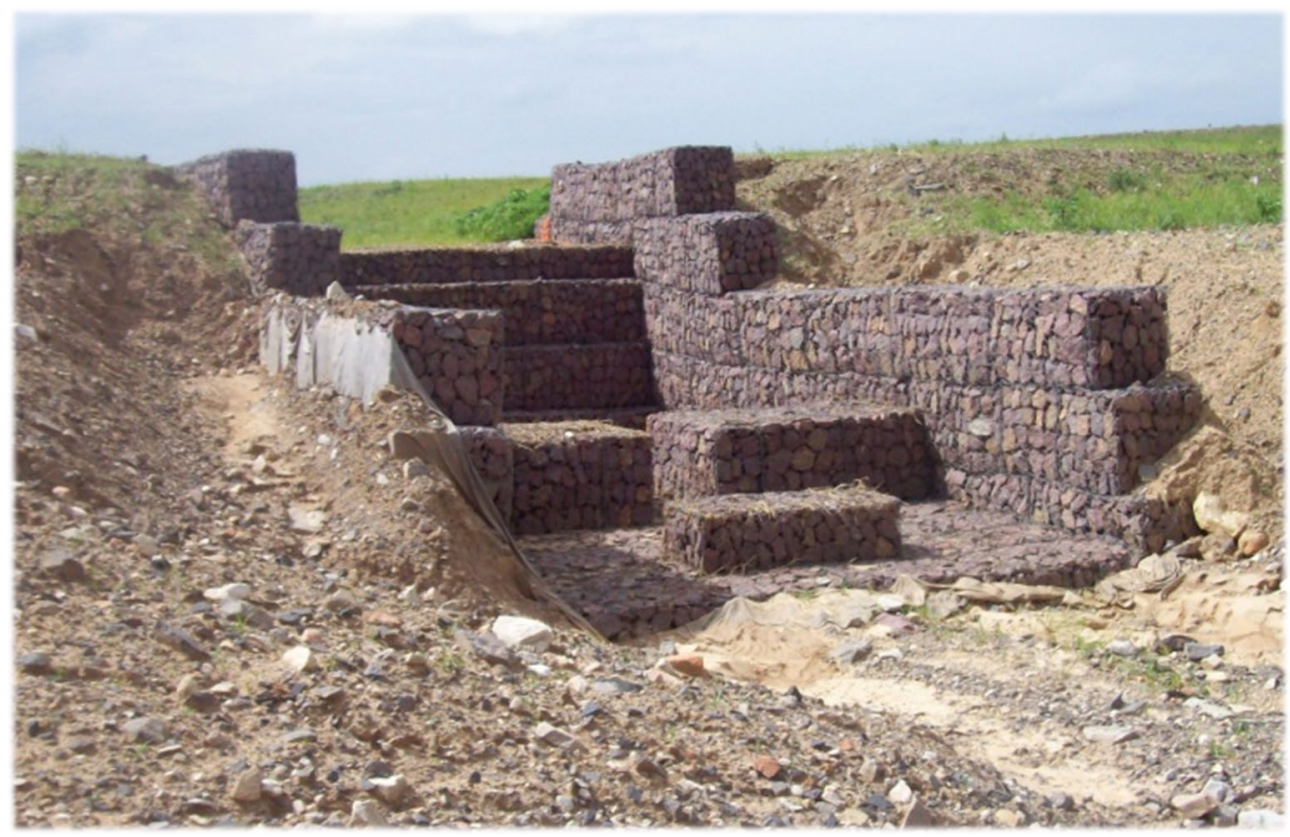

Figure 7 Soil loss: expose erosion control structures and imminent failure 


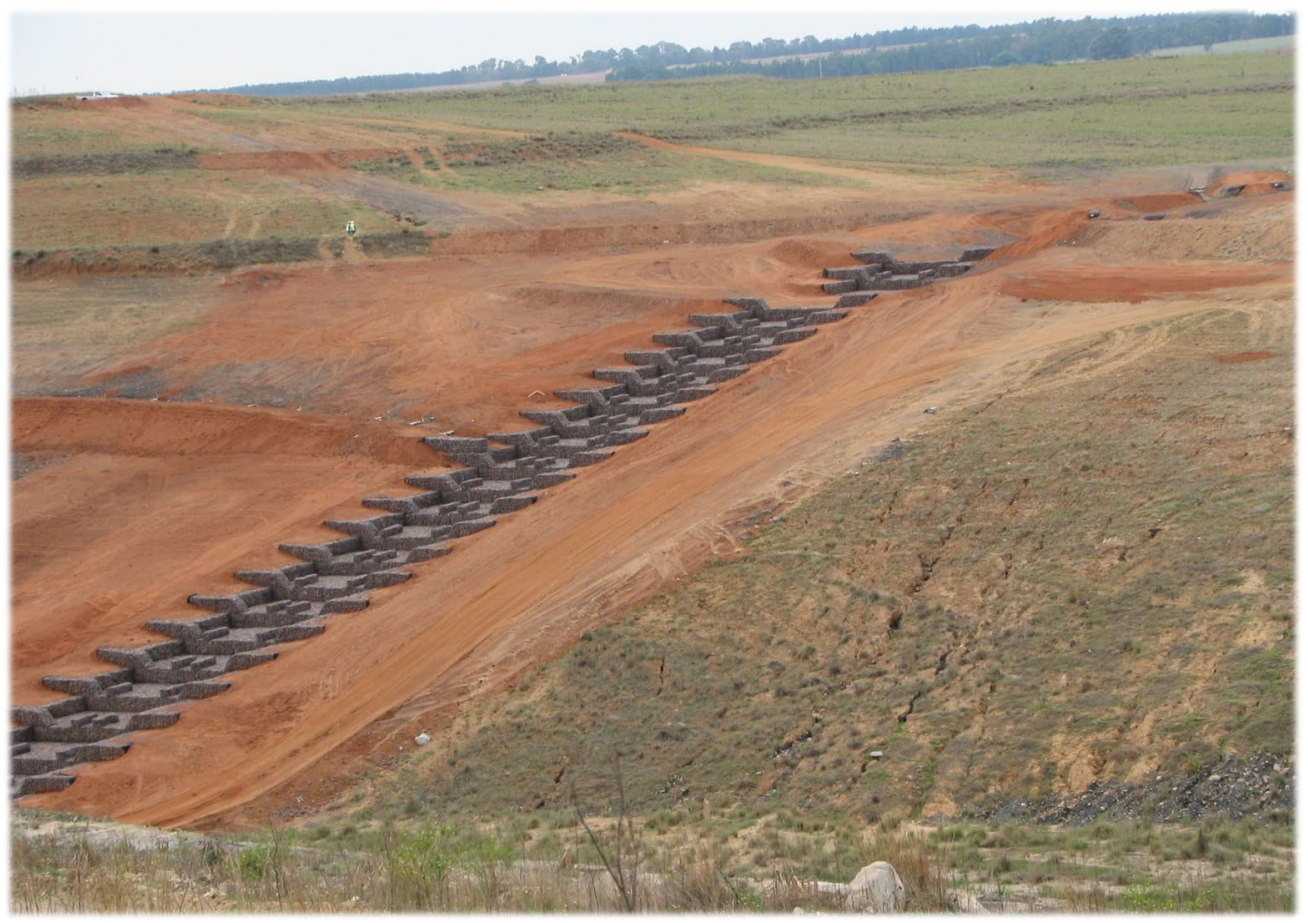

Figure 8 Gabion chute structure with exposed erosion gullies after first substantial rain event

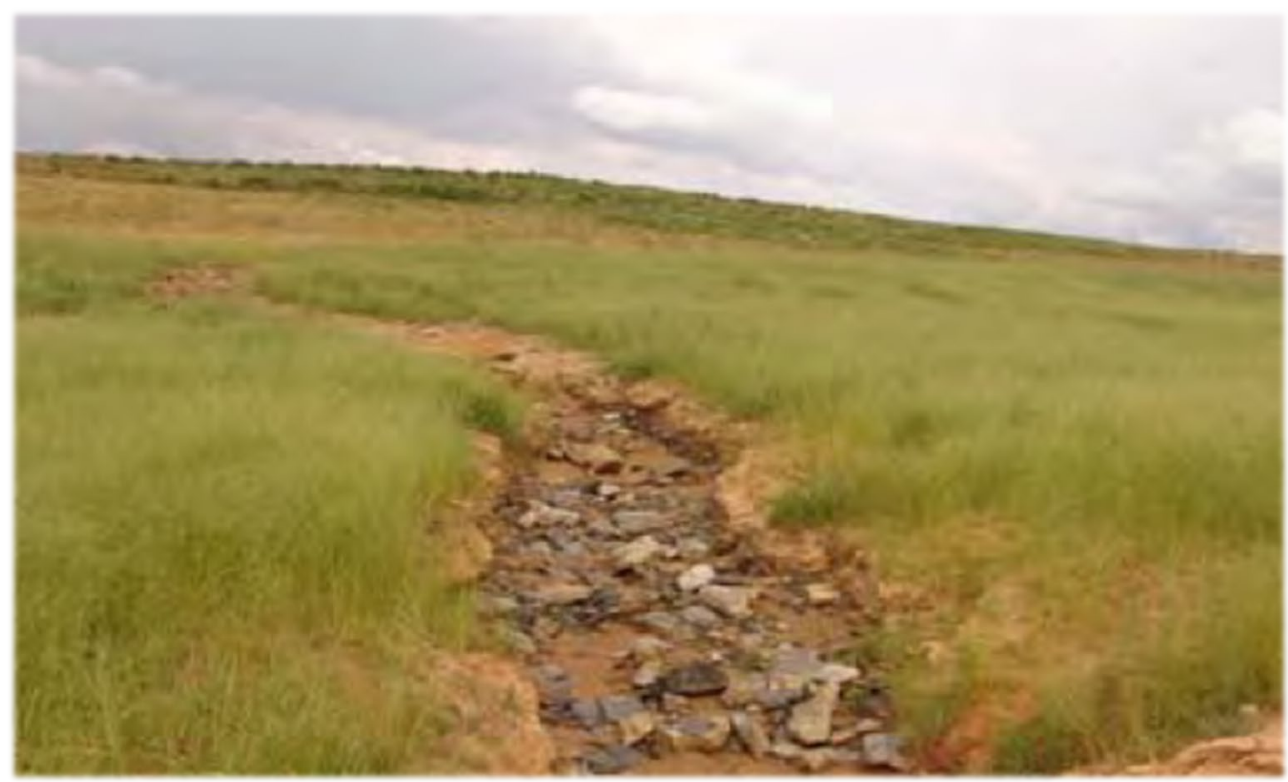

Figure 9 First rain season: exposure of spoil material

The legacy of slope selection during final design of an open pit rehabilitation will have a significant effect on the risk profile of the final landform and more so in the introduced risks in rehabilitation activities. The closure planning and associated costings are highly influenced by the final design criteria. Design inefficiencies will lead to structure failures that will, in turn, create erosion gullies and trenches. The repair of these failures is not only costly but exposes the work teams to unnecessary risk by having to work on steep slopes.

\section{The use of emerging technologies to ensure best practice}

Digital solutions can help mining companies reduce complexity and optimise business and operational performance. Modern mines should shift their focus towards operational efficiency to stay ahead of the curve. This change is challenging for most industries, including the mining industry. The truth is that many 
mining companies are still very hesitant about furthering their digital mining transformations for fear of cost, uncertainty, and mostly, fear of the unknown.

However, what mining companies need to know is that technology across the interdependencies between cloud storage and transmission, as well as Big Data and associated analytics, mobility and social as well as innovation collaborators (e.g. internet of things, next-generation security, cognitive processing, and augmented reality and virtual reality) are critical to reshaping mining companies and their operations. These technologies have the ability to re-engineer processes and activities within the mining industry from planning, during operations, and through to closure. In the closure stages of any mine project, this transformation will add significant value to the closure teams and more so to community stakeholders.

Additional benefits from digital transformation include mobility, cloud, and sensing analytics, remote security and network options and accessibility of data to stakeholder communities (Figure 10).

Establishing a low power, long-range, wide area communications data network that can interface with a range of real-time sensor data and networks initiates a multitude of new opportunities. The early installation of monitoring equipment will deliver great cost effectiveness during the operational phase and well into the closure phases. The instrumentation type, location, and monitoring frequency should be selected based on appropriate controls identified during closure risk assessments. This technology presents an opportunity for the accumulation of a wide range of data sets that will add great value to the decisions and designs relating to the construction and monitoring of final closure solutions. Monitoring data may be used to justify to local regulators that a mine site has been left in a safe and stable condition and that the mine operations have met their obligations.

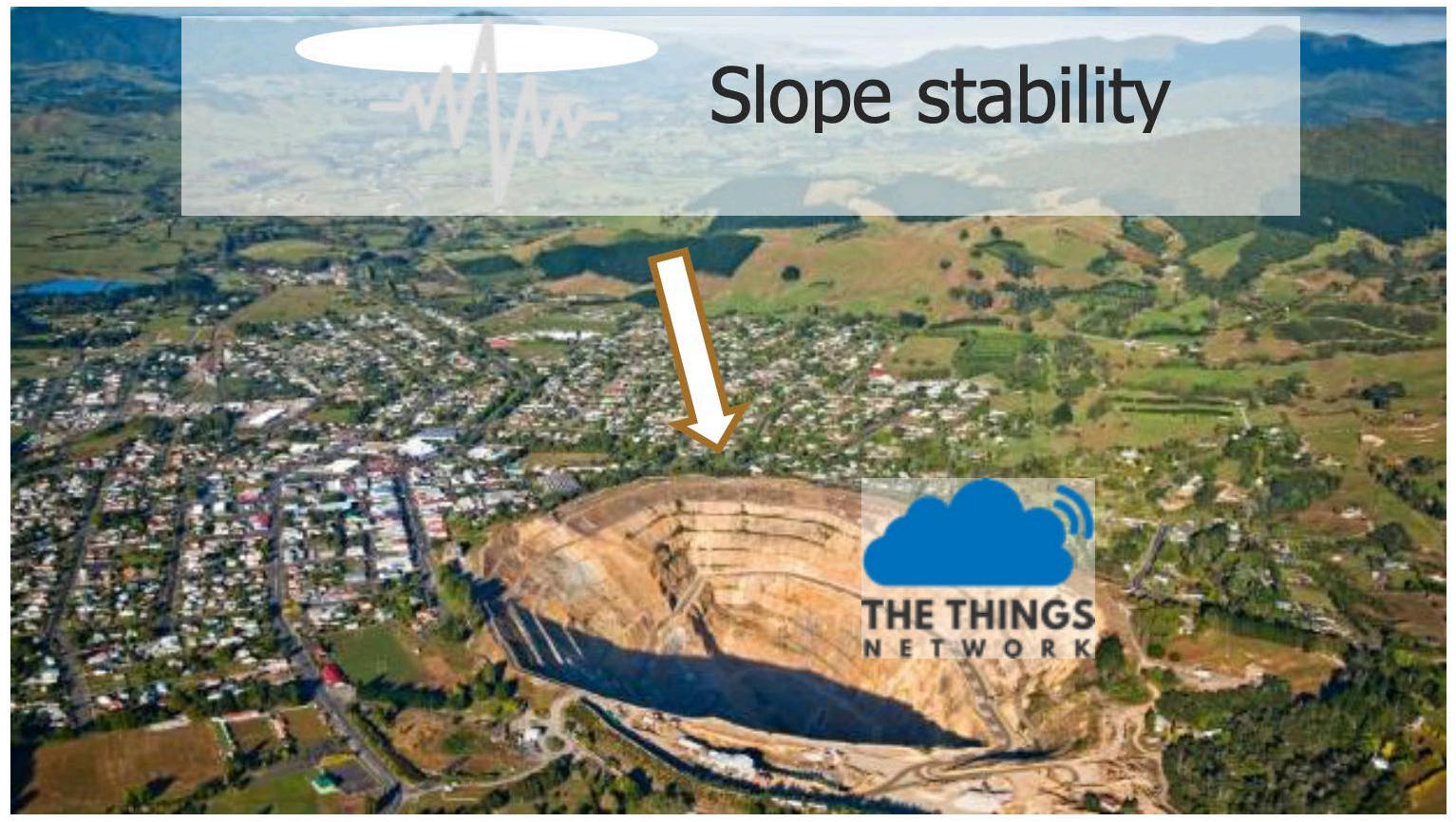

Figure 10 Slope stability monitors through Wi-Fi within an integrated network (Bowler 2018)

Back to the Future (Canton \& Gale 1985) should be a virtual reality interactive experience, during which board members and senior executives are donning virtual reality glasses that allows them to journey into any new mining project from exploration to the final relinquishment of the mine. This experience should not merely excite but also caution them of the importance and risks of failed stakeholder engagements. The visual effects in such an interactive experience will be able to assist in highlighting the benefits of concurrent rehabilitation by eliminating delayed soil cover and therefore, avoiding erosion gullies as well as limiting the water ingress into the voids. Augmented reality can facilitate the visual effect of the mine voids rapidly filling with water. This water will eventually decant into streams and rivers as polluted acid mine drainage. Pollution from mines need to be managed and in the instance of water, most treatment options are very costly (Reverse osmosis etc.). 
Concurrent rehabilitation aims to reach a final landform as soon as possible and then to apply top soil cover and revegetate. In doing this as quickly as possible, the cost over time is drastically reduced in terms of the previously mentioned cost generating repair activities.

\section{$6 \quad$ Closure costs}

Cost estimation at the appropriate level of accuracy is critical. Most closure projects have a large component of uncertainty due to historical intervals. A significant number of closure projects will be initiated from abandoned sites, with these scenarios highlighting the need for well-designed planning.

Closure costs are almost as site-specific as geology, but generalisations can be used to indicate the range of possible costs. On the low end of the spectrum, small mines in Romania cost around USD 1 million to close and rehabilitate. On the other end of the scale, closure costs for large lignite mines in Germany run to hundreds of millions of dollars (World Bank 2002).

The cost of closure tends to be considerably lower in instances where the owner/operator of the mine conducts concurrent rehabilitation that leads into the closure and final process. The World Bank reported that significantly higher costs tend to be associated with state-run clean-up due to the lack of familiarity with the site (World Bank 2002).

Early cost estimates are critical. Accurate, timeous estimates are necessary to ensure that sufficient funds are available towards the end of the mine's life. The estimates should be updated systematically every five years for a 30-year life-of-mine or every two years for a 10-year life-of-mine (World Bank 2002). Concurrent rehabilitation can save tens of millions of dollars in rehabilitation costs at closure.

\section{Conclusion}

Planning for closure starts at the concept level and when being supported by improved rehabilitation designs and planning, will facilitate concurrent rehabilitation. Well thought out trials and expenditure during concurrent rehabilitation will significantly reduce overall closure cost provisioning.

Stakeholder engagement mimics the project highs and lows and may ultimately highlight the success or failure of a closure project even though all the other processes were designed and executed within practicable parameters. Open and continued communication with all stakeholders will eliminate unnecessary delays in the project as well as promote collaboration with new stakeholders in the light of re-use, repurposing, and ultimately relinquishment of an asset or site.

Quality in design and quality control during execution is critical in delivering a project that measures the final outcome versus the initial planning. Design changes in the form of improvement opportunities or the implementation of new technology may occur during the execution of the project. Emerging technologies should be embraced as a value-add and time and effort spent on this will be well rewarded.

Due to the time consuming nature of closure projects, the impetus dwindles as team members and stakeholders change. New unforeseen challenges and changes in legislation may also present opportunities to engage with authorities and in doing so strengthen the relationship and support for the project.

Once the aforementioned has been achieved, more effective closure cost modules can be produced and replicated as and when needed in the new closure projects.

Implementing the planning and progressive rehabilitation learnings will lead to better foresight for final closure solutions. The review of inappropriate hindsight learnings will benefit closure teams and improve better closure project delivery. 


\section{References}

Botha, R, Muhlbauer, R \& Human J 2018, 'A stitch in time saves nine: a case study of the importance of quality water models and surface rehabilitation to optimize closure options', in C Drebenstedt, F von Bismarck, A Fourie \& M Tibbett (eds), Proceedings of the $12^{\text {th }}$ International Conference on Mine Closure, TU Bergakademie, Leipzig, pp. 532-539.

Bowler, M 2018, GHD Marketing Presentation, GHD Pty Ltd, Melbourne.

Canton, N \& Gale, B 1985, Back to the Future [Motion Picture], Universal Studios, USA.

Google 2010, South Africa, Mpumalanga Province road between R545 and R547.

Grant, C, Lacy, H, Ferguson K \& Heyes J 2018, 'Words, words, words: but what is the matter, my closure lords', in C Drebenstedt, F von Bismarck, A Fourie \& M Tibbett (eds), Proceedings of the $12^{\text {th }}$ International Conference on Mine Closure, TU Bergakademie, Leipzig, pp. 15-22.

Skousen, J \& Zipper, CE 2014, 'Post-mining land use options in the Appalachian coal mining region of the USA', Proceedings Life-ofMine, The Australasian Institute of Mining and Metallurgy, Melbourne.

World Bank 2002, It's Not Over When It's Over: Mine Closure Around the World, World Bank Group's Mining Department, Washington. World Bank 2003, Elements of Good Mine Closure Planning, World Bank Group's Mining Department, Washington. 
